\title{
INÚTIL REBELDÍA DE CETI LEREDI EN RELACIÓN CON SU MATRIMONIO (SIGLO XV)
}

\author{
ENCARNACIÓN MARÍN PADILLA \\ CSIC. Madrid
}

El presente estudio ${ }^{1}$ está dedicado a la inconformista personalidad de Ceti Leredi, nieta de Juce Gallur e hija de Hahim Leredi y de Duenya Gallur. Ceti, que intentó rebelarse contra su concertado matrimonio con Jaco Abenbitas, residió en Epila, villa aragonesa del señorío de los Ximénez de Urrea desde los últimos siete años del siglo XIV.

Los antecesores paternos de Ceti, los Leredi, eran «stados naturales de la villa de Epila». Uno de ellos, Salamon, residió algún tiempo en Calatayud, de donde volvió a la villa en 1447 con su hija Bellita, porque allí vivían su padre Acach y sus hermanos. Acach Leredi fue corredor público de la aljama en 1449 y 1458, y corredor de la corte del merino en 1451, 1456 y 1458. En 1459, fue nuncio de esta corte otro miembro de la familia Leredi, Jaco. Pero de Hahim Leredi nada se sabe, aparte de su matrimonio con Duenya Gallur ${ }^{2}$.

Por lo que se refiere a los antecesores maternos de Ceti Leredi, se remotan al siglo XIV en Épila. El primer miembro de la familia Gallur que, según la documentación, residió en la villa en el último cuarto del siglo XIV fue Mosse Gallur ${ }^{3}$. Mosse estuvo casado con doña Sol

\footnotetext{
${ }^{1}$ Su base documental procede del Archivo de Protocolos Notariales de La Almunia de Doña Godina (L.A.APN.), en su mayor parte, y del de Zaragoza (Z.APN.). Dada la limitación de páginas de este homenaje y porque de todo lo que aquí expongo doy más extensas noticias en mi trabajo, La villa aragonesa de Épila en el siglo XV: sus judíos [en prensa], prescindiré de las notas que no son base fundamental de éste. Todas las personas nombradas residicron en Epila, villa donde ocurrieron los hechos narrados; si no fuera así, se hará constar.

${ }^{2}$ La mayor parte de las noticias de este trabajo se refieren a los años cercanos a los hechos narrados, 1445-1460, aunque se aluda a hechos que tuvieron lugar antes y después.

${ }^{3}$ A él me referí en mi artículo «La villa aragonesa de Épila en el siglo XIV: sus judíos», Sefarad XLVII (1987) 315-344.
} 
de Stallo, de cuyo matrimonio nacerían, entre otros, Acach, que se casó con Bellita de Zucran, y Juce Gallur. A comienzos del siglo XV éste último tenía sus casas en el barrio de El Burgo, donde también residían Orduenya Gallur y su marido Simuel Alcarahuey. Juce Gallur casó con Ceti Altexefi y, entre otros, tuvieron un hijo, al que Juce impuso el nombre de su padre, y una hija, Duenya, que casó con Hahim Leredi y fueron los padres de la rebelde Ceti.

Pero de todos los Gallur quien logró más relevancia en la villa fue Jossuas Gallur, que estuvo casado con Clara Almali. Jossuas, además de hacer préstamos en comandas, desempeñó las siguientes funciones, entre 1445-1460: adelantado y arrendador de la sisa de la carne y harina en 1445; procurador de judíos de Zaragoza y de escuderos de la villa; "collidor» del peaje o pontaje de la villa, en nombre del señor don Lope, en $1445,1447,1449,1450,1451,1453$ 1454, 1456 y 1459; arrendador, a medias, de la sisa de la carne y vino de la aljama en 1448, año en que volvió a ser adelantado, como lo era en 1458; y receptor del dinero de la carnicería y otros emolumentos del concejo en 1452. Residió Jossuas Gallur en el barrio de La Plaza, en unas casas que lindaban con el hospital de los pobres cristianos ${ }^{4}$; en 1460 Jossuas compró, por doscientos sueldos, otras casas en el barrio de Las Herrerías ${ }^{5}$. Jossuas y Clara tuvieron también casas en Zaragoza y posesiones en Navarra.

Pero volvamos al personaje principal de este estudio, Ceti Leredi. La infancia de Ceti transcurriría, como la de cualquier niña de su edad, junto a sus padres, en las casas que éstos tenían en el barrio de Las Herrerías ${ }^{6}$.

A la muerte de Hahim Leredi quedó Ceti y su hermano Juce con su madre Duenya, que contrajo un segundo matrimonio con rabí Abraham Albo en $1438^{7}$. Diez años después, la vida volvía a golpear a la pequeña Ceti.

En junio de 1448, concretamente el día 19, encontrándose Duenya

${ }^{4}$ Con las de Acach Sumiel, con las de Saya Sumiel, con las del escudero Pedro Garcés de Rueda y con carrera pública.

${ }^{5}$ Que lindaban con las de Salamon Levi, con las de Abraham Carfati y con callizo, por donde tenían su entrada y salida.

${ }^{6}$ Que lindaban con las de Martín de Ateca, con las de la capellanía que tenía el clérigo Gaspar Navarro, con carrera pública y con el muro. Poseía también el matrimonio una viña en Los Montarones.

7 El contrato matrimonial entre rabí Abraham y Duenya se hizo el día 10 de «ho del anyo de cinqu mil cient e novanta e gueytom de la creación del mundo, del dé anvu judio, lo estifís el propio ráí Abraham, como notario público de la aljama de los judíos de la villa. enferma ${ }^{8}$ pensó disponer de los doscientos sueldos que rabí Abraham le «firmo en sus arras». Duenya quiso que, a su muerte, dicha cantidad se la entregara éste a su hija Ceti en «ayuda de su casamiento". Luego nombró tutores y curadores de Ceti a Salamon Sumiel, marido de Soli Gallur, a Acach Abenforna, hermano suyo y tío de Ceti, y a Juce Leredi, hijo suyo y hermano de la menor ?. No hizo Duenya mención alguna de otro hijo suyo y de Hahim que, por entonces y después de su conversión al cristianismo, fue clérigo misacantano y canónigo del monasterio de San Jaime de Calaf, en el señorío del conde de Cardona, del principado de Cataluña; se llamaba Juan de Marín.

El 3 de febrero de 1449, los tres hermanos Leredi, el clérigo Juan, Juce y Ceti otorgaron carta pública de «diffinicion general» rabí Abraham Albo, a sus bienes y a sus sucesores, de cualquier demanda y acción que pudieran promover sobre las casas, la viña y otros bienes muebles e inmuebles que les pertenecieran por herencia de su difunta madre Duenya y que a ella le firmó como «aras e axuar» Hahim Leredi, padre de los tres. A continuación, Ceti recibió de rabí Abraham los doscientos sueldos que su madre le dejó en su testamento ${ }^{10}$.

Aunque Duenya Gallur ordenó en su testamento que los doscientos sueldos fueran para ayudar al casamiento de Ceti y ésta los había recibido, había otra cantidad a la que Ceti, al parecer, tenía derecho cuando se concertara su matrimonio. El 4 de mayo de 1450 , Juce Leredi, que vivía temporalmente en Zaragoza, recibió en comanda del tejedor Acach Abenforna, uno de los tutores y curadores de su hermana Ceti, trescientos sueldos ". Pero quedaba "en fe» que Juce entregaría dicha cantidad a la joven cuando le saliera buen matrimonio y «predra partido de prender su marido», y que Acach le cancelaría la comanda, pues "en razon del matrimonio» se hizo ${ }^{12}$.

${ }^{8}$ Pero «por gracia de nuestro Senyor Dios en su buen'seso, firme memoria et palavra maniffiesta».

${ }^{9}$ L.A.APN., Martín Marín, 1448, fol. 48v: testigo con el merino Miguel de Fuertes, Jaco Gotina.

${ }^{10}$ Dicho notario, 1449, fols. 9-10v: testigos con Juan del Tuo, Jossuas Gallur y e «cilurgico» Mosse Cariello.

${ }^{11} \mathrm{Y}$ tomó quinyan «en la falda de buen panyo» de Salamon Sumiel (dicho notario, 1450, fol. 28v: testigos con Antón del Tuo, Salamon Sumiel, mayor, y Salamon Levi).

${ }_{12}$ Juce juró en poder de Salamon Levi, sobre la ley de Moisés, darlos en el plazo de quince días, cuando Acach lo requiriera para hacerlo (dicho notario, año, folio y testigos). 
Transcurridos unos meses, Acach Abenforna ${ }^{13}$, uno de los tutores y curadores de Ceti, sin contar con los otros dos y sin que la interesada lo supiera, arregló el matrimonio de la joven con Jaco Abenbitas, que residía en el lugar de Muel. Acach convenció después a su sobrina Ceti de las ventajas de este matrimonio, alabando al novio y haciéndole dueño de riquezas y cualidades que, al parecer, estaba muy lejos de poseer.

La joven Ceti aceptó el matrimonio con Jaco, pero cuando descubrió sus no tan grandes medios de fortuna y su gusto por el juego y las mujeres, su negativa fue rotunda.

La inconformidad de la joven, respecto a su matrimonio, sorprendería a sus más cercanos allegados, entre los que se encontraría su padrastro rabí Abraham Albo, de cuyo fuerte y dominante carácter dan muestra lós más de un conflicto con los miembros de la aljama. El resto de la comunidad judía, incluidas las mujeres, tampoco apoyaría la actitud adoptada por Ceti, que no se mostraba nada dócil, hasta el punto de asegurar que «sabria antes morir e tomar otra ley por virtut de la que oy no tengo»; cosa que antes había hecho su hermano Juan. Sin «abrigo ninguno» por parte judía, excepto el de su hermano y sus tíos Soli y Salamon, según parece, desesperada y sola la valiente joven pensó que podrían ayudarla señoras cristianas cercanas al señor de la villa y solicitó ser recibida por doña Jaima Ruiz, mujer de don Francisco Muñoz, procurador general del señor don Lope Ximénez de Urrea, y por doña Juana Muñoz, mujer de don Juan de Valconcha. Esperaba Ceti que, una vez expuesto su delicado caso, las señoras obrarían con justicia y aceptarían su petición de que se la acogiera en casa de sus tíos Soli Gallur y Salamon Sumiel. Su solicitud de audiencia fue aceptada.

El domingo 4 de octubre de 1450 , en las casas del señor don Lope Ximénez de Urrea, donde estaban preséntes las señoras Jaima Ruiz y Juana Muñoz, además de Salamon Sumiel, Duenya (sic) ${ }^{14}$ Gallur y Juce Leredi, tutores ${ }^{15}$ de Ceti Leredi, y otras personas de bien, compareció Ceti Leredi y, ante todos ellos, el notario cristiano y los testigos, les dijo:

«Senyoras e honbres buenos, la causa e razon'por que yo de

${ }^{13}$ Vivía también en la villa otro Acach Abenforna, escritor de letra judaica.

${ }^{14}$ El nombre aparece entre líneas. Quien sí asistió a la audiencia fue Soli Gallur.

15 La palabra aparece entre líneas. Duenya no era tutora de Ceti. present so venida aqui, se ys por tanto que mi tio Acach Abenfforna .. con algunos otros con el ensemble, con voluntat formada e sine de ninguno voto e voluntat mia ni de mis tutores, en absencia mia, ellos me desposasen e dassen palavra por mi de casarme con Jaco Abenbitas ... diziendome como el dito Jaco hera jodio asaz joven e muy epulento en riqueza e buen menestral e que yo casando con el seria de muy buenha ventura; asi que en tal manera me composaron en razon, que yo presumiendo quel dito Acach Abenfforna, atento seyer a mí tio, no me diria sino toda verdat, yo les atorgue a fazer aquello qui el e los otros tovian de aqueste acto e me aconsellavan; de manera que la cosa vino segunt ellos quisieron, qui el dito Jaco Benbitas vino aqui e yo me desposse con el, lo qual vos certeffico e con toda verdat que si antes de yo atorgarles el acto que les atorgue, yo no lo havia feyto, atento lo havies visto antes de la hora pora la hora, visto que no hera a fazer a mi por la cosa seyer tan publicada, yo bien deliberado a fazer todo lo qui ellos quissieron; por do agora, senyoras e honbres buenhos, que me so recosirada e hovido verdadera relacion de la vida, stado, si quiere manera del dito Jaco Abenbitas, quien ys ni de que manera ni como bive ni como no, yo me lexaria antes morir que yo casase con el, car lo primero e principal el ha luego fallido a los pactos e convenios feytos e firmados entre mi e el lo segundo el no tiene lo medio de aquello que me prefirieron el tenia, lo tercero el ys muyt gran jugador de jugo de dados, hoc y en tal manera que vegadas viene segunt yo so bien infformada que no se lexa cosa ninguna de lo suyo que no se lo juege. Item mas, el ys muy rasero que sé que tiene muytas mancebas, do por causa de aquellas se degastaria su casa por buenha que fuese e yo nuncha havria buenha vida con el. Assi que por todas las razones sobreditas y otras asaz que yo poria recontar del, vos certiffico en ningun partido del mundo yo nuncha casare con el, antes como digo sabria antes morir e tomar otra ley por virtud de la que oy no tengo. Et por quitarme de todos los inconvenientes sobreditos, atento seyer joven e no tener de present abrigo ninguno qui a mi en aqueste paso talmente me pueda ayudar a mi justicia, mende so venida aqui a poder de vosotras, senyoras, como a duenyas honorables e personas que de aquesta parte me daredes consello a mi justicia. Et no entendays, senyoras e honbres buenhos, que aquesto que de present vos digo, vos lo digo porque yo sia infformada de ningunas personas que quirian mal ni ayan mala voluntat del dito Jaco, antes de personas que saben todo aquesto como yo lo digo, e mi hermano Juce Leredi que ys stado con el [palabra ilegible] con el de despues que el se desposo con mi; porque, senyoras, la hora pora la hora vos digo que plaziendo a mi cunyado [sic] Salamon Sumiel ..., asi como a tutor e curador de la persona e 
bienes mios, dexado a el en custodia e guarda mia por mi padre e madre mia, que Dios aya, e de Soli Gallur, muller suya e tia mia que presentes son, que yo amaria star en casa suya mas que en casa ninguna de jodio otro ninguno de aquesta villa, suplicandovos de mi part abenga tanta gracia de vosotras mi querades recomandar, que por su vondat, atento ys mi tutor e persona de la qual yo nonde puedo haver sino todo bien e toda, honor, me quiera tener en su casa».

Cuando Ceti terminó de hablar, le preguntó doña Jaima Ruiz:

«Vehamos filla, tu antes que vinieses aqui, as venido por infloio de ninguno ni por menaças que ninguno te haya feito, car no querria que en aquesta parte tu mende enganyases».

Ceti le contestó:

"Senyora, yo no so venida aqui por infloio de ninguno ni por cosa otra ninguna, sino por foyr a los inconvenientes sobreditos».

Entonces doña Jaima rogó a Salamon Sumiel y a su mujer Soli que

«tomasen a la dita Ceti ... en su tomada e guarda fius atento que por el sobredito don Francisco Munyoz ... fuese mandado otra cosa en contrario".

A la petición de doña Jaima contestaron Salamon y Soli, así:

«Senyora, pues voluntat vuestra ys quella vinia a poder nuestro ..., nosotros somos prestos e parellados por tanto a tomar aquella en guarda e comanda vuestra daqua ... que por el dito procurador o por vos, pues nos la intimades, quanto mandado de ella devamos fazer» ${ }^{16}$.

No se sabe con quién y dónde vivía Ceti — tal vẹz con su padrastro rabí Abraham- antes de su comparecencia ante las dos señoras cristianas pero, a partir de entonces, quedó bajo la guardia y custodia de Salamon y Soli.

${ }_{16}^{16}$ L.A.APN., Martín Marín, 1450, fols. 76-77: testigo con Miguel de Fuertes, Ezdra Gaddax Los efectos de la humedad hacen casi ilegible parte de este instrumento público notarial.
La permanencia de la joven en casa de sus tíos fue muy corta, sólo dos o tres días. ¿Intervino el despreciado Jaco Abenbitas y medió rabí Abraham, padrastro de Ceti, o tomaron cartas en el asunto las autoridades de la aljama, considerando que la cuestión debía resolverse en el seno de la comunidad, de donde nunca tuvo que trascender? ¿Se puso el hecho en conocimiento de don Lope, señor de la judería y con autoridad civil sobre sus vasallos? $Y$, finalmente, ¿de quién partió la idea de retirar a Ceti de casa de sus tíos? Nada se sabe; sólo consta que el procurador general del señor, don Francisco Muñoz, que se encontraba en Aranda, escribió el día 6 una carta al merino Juan Sánchez de Sarriá con orden de que fuera a recoger a Ceti y la tomara «a mano suya».

Recibida la carta, el merino se personó el miércoles, día 7, en las casas, «si quiere habitacion», de Salamon Sumiel, al que acompañaban su mujer Soli, rabí Abraham, padrastro de la joven, y «asaz otros jodios de la aljama». Allí, ante el notario cristiano y los testigos, le dijo:

«Salamon Sumiel, yo he havido una letra del honorable Francisco Munyoz ... faziendome saber por virtut de aquella que yo tome a mano mia a Ceti Leredi, jodia sposa de Jaco Abenbitas, la qual vos, me dize por su letra, tomades a vuestro poder ...; vos mando de parte del dito procurador e vos ruego de la mia, vos me querades dar a ... Ceti».

\section{Salamon le contestó}

«que aquel mandamiento el metia sobre su cabeça e que quanto a la restitucion quel le demandava de la dita Ceti Leredi, que aquella no hera en su poder. Et que era verdat ella hera stada en su casa en los dias pasados, la qual havia stado acomendada por la senyora dona Jayma ..., que pues en su poder ella no hera no ge le pudia restituir».

El merino volvió a insistir en que se la entregara,

«pues mandamiento el havia aquella tomar a mano suya e que aquesto le mandava ge le das en poder suyo, jus pena de mil solidos aplicadores a los cofres del senyor don Lop Ximenez d'Urrea».

Salamon se mantuvo en lo dicho y el merino en su petición, 
amenazándolo, además, con mandarlo «yr preso a su casa con su muller ensenble con él»; y requiriendo, a continuación, al notario cristiano para que levantara acta pública de todo lo dicho ${ }^{17}$. Después de volver a decirle Salamon al merino «aquello que en principio havia respuesto», añadió

«que a mayor descargo suyo, que le dava poder mirar toda su casa e que si alli la trobava que no se condepnaria en los sobreditos mil solidos mas en dos mil e que aquesto dava por respuesta a todas otras resquestas ...; e en cara a su muller fue requerido de la sobredita respuesta por el feyta, lende fizo carta publica; e que hera presto e parellado de hir preso como de continent fizo, a la casa del dito merino».

Finalmente dijo Salamon:

«Fazedes vos, merino, e todo quanto en aquesto se faze ni a feyto, se a feyto e faze por consello vuestro»

Entonces el merino volvió a requerir al notario cristiano para que levantara acta pública ${ }^{18}$.

¿Dónde estaba Ceti mientras se hacía el requerimiento: en Épila o fuera de la villa? ¿Quién la tenía escondida? ¿Supieron que el procurador del señor iba a reclamarla y la escondieron? Aunque la propia joven pidió a las señoras cristianas que la dejaran con sus tíos y éstos consintieron, ¿huyó Cetil luego de la casa por su propia voluntad, al darse cuenta de que Salamon y Soli le retiraban su apoyo ante fuertes presiones, o se fue de la casa sabiéndolo sus tíos? La documentación no dice nada más sobre el caso. Lo que pasó en los días que mediaron, desde la entrega de Ceti, que'hizo doña Jaima a Salamon y Soli, hasta su desaparición, sus miedos, desesperanzas y presiones quedan en el más absoluto secreto, lo mismo que el enfoque y la postura de las autoridades de la aljama, respecto al caso.

La vida de Ceti no había sido fácil. Primero, la muerte de su padre, a la que siguió el matrimonio de su madre Duenya y la aparición en la vida de la joven de su padrastro rabí Abraham,

${ }_{17}^{17}$ "Con conservacion de su dreyto a su tiempo e lugar demostradera».

18 Dicho notario y año, fols. 79v-80: testigo con Antón del Pucke, Juce Albo. Lo dicho en nota 13 sobre los efectos de la humedad sirve también para estos folios. además de la conversión de su hermano y el contratiempo que supondría para toda la familia. Después, la muerte de su madre y el control de su persona y bienes por sus tutores y curadores, en especial por su tío Acach Abenforna que, sin contar con los demás y con la ayuda de personas extrañas - que nada tenían que ver con Cetiacordó su matrimonio. La joven Ceti parecía estorbar a sus parientes $y$, aunque nada se sabe en concreto de la actitud adoptada sobre el caso por sus hermanos Juce y Juan, su rebedía, tal vez inesperada, y su amenaza de conversión tuvo que molestar sobremanera a rabi Abraham, entre otros. Ceti se adelantó a su tiempo, pero todas sus luchas, peticiones, ruegos y esfuerzos, por disponer de su vida, terminaron en un rotundo fracaso, que la obligaron a aceptar su matrimonio con Jaco Abenbitas y las normas prescritas, como hacían todas las jovenes de su comunidad. A partir de su sumisión, nada más se sabe de su persona, que parece haber caído en el más absoluto de los anonimatos. Sólo nos consta que de su matrimonio con Jaco nacieron, al menos, tres hijas: Oro, de la que fueron tutores Sento Gallur y su tío Juce Leredi y que, luego, casó con un hijo de Sento Amiello; Duenya, que casó con Simuel Sumiel, hijo de Salamon Sumiel; y una tercera, que se convirtió como su tío Juan, que se llamó después de su bautismo Beatriz de Riglos, y que pasó a residir a Zaragoza.

Por lo que se refiere a Jaco Abenbitas, una vez resuelta la cuestión de su matrimonio y asentado en la villa, ejercería aquí su oficio de sastre, cuyas ganancias acrecentaría con las entregas de comandas a moros de Muel ${ }^{19}$ y de Alfamén ${ }^{20}$ en los años 1451-1453.

No se sabe qué pudo decidir a Jaco a recibir, el 2 de mayo de 1455 , del concejo de la villa ${ }^{21}$, reunido en la Plaza, el pequeño huerto de la capellanía de San Nicolás ${ }^{22}$, sito cerca de «La Penya el Palacio», por un treudo perpetuo de un sueldo tres dineros anuales. Motivó tan

${ }_{19}$ El 12 de febrero de 1451, ciento veinte sueldos a Mahoma la Roya, de los que éste respondió con sus casas y un huerto; y el 29 de octubre del año siguiente, veinticuatro florines de oro a los hermanos Mahoma Pellalbo y Mahoma de Monder, de los que respondió el primero con una mula (dicho notario, 1451, fols. 30-30v y 1452, fol. 124).

${ }^{20}$ El 2 de abril de 1453, veintiocho sueldos a Lop de Cayt, quien se los pagó el 22 de marzo del año siguiente (dicho notario, 1453 , fol. 26 y 1454 , fol. 46 ).

${ }^{21}$ Infanzones y labradores, convocados por el corredor Rodrigo Barahona.

22 Perpetua, «celebradera en las eglesias de fuera» de la villa, y de la que el concejo era patron y dador. 
bajo treudo que el capellán tenía el huerto «dormido e gastados y que el concejo quiso que diera algún provecho ${ }^{23}$.

El comportamiento de Jaco Abenbitas debió de mejorar después de su matrimonio con Ceti porque, en marzo de 1461, desempeñaba el cargo de adelantado de la aljama, junto con Saya Sumiel, mayor, y con Salamon Levi ${ }^{24}$ :

El 28 de marzo de 1463 y después de que en enero actuara como testigo instrumental, el sastre Jaco Abenbitas pagaba. a Paricio de Mata, clérigo misacantano y beneficiado en la iglesia de Santa María, los quinientos sueldos que le debía en comanda ${ }^{25}$.

Dos años después, en 1465, Jaco vivía en unas casas que lindaban con las de Salamon Afla que, a su vez, lo hacían con las de García de Soria y con dos carreras públicas ${ }^{26}$. Transcurridos diez años, las casas de Jaco, en la carrera de El Burgo, lindaban con las de Abraham Afla y de su mujer Orduenya Eli ${ }^{27}$.

La última noticia que alude a Jaco Abenbitas en Épila, data del 23 de febrero de 1484, cuando actuaba como testigo instrumental al recibir su cuñado Juce Leredi y su sobrino Hahim Leredi, hijo de éste, una comanda ${ }^{28}$.

En los primeros meses de 1491 fallecería Jaco Abenbitas y es muy posible que Ceti Leredi hubiera muerto antes que él; su hija Oro necesitó tutores. El matrimonio Jaco-Ceti habría pasado a residir en Zaragoza, según pareció indicar su hija Beatriz.

Por lo que se refiere a sus tres hijas, la relación existente entre Oro, Duenya y Beatriz fue buena, hasta que trató de enturbiarla Simuel Sumiel, marido de Duenya. Con el firme proposito de que éste no lograra su deseo, la conversa Beatriz emprendió viaje desde Zaragoza hasta el lugar de Urrea.

El 2 de octubre de 1491 en dicho lugar, la zaragozana Beatriz de Riglos absolvió y defeneció a su hermana Oro Abenbitas, que residía en la villa de Épila, como heredera de los bienes de sus difuntos padres Jaco Abenbitas y Ceti Leredi, a Sento Gallur y Juce Leredi, como

${ }^{23}$ El treudo debería pagarlo Jaco el día de San Miguel, en septiembre, o siete meses después (dicho notario, 1455, fol. 83).

${ }^{24}$ Dicho notario, 1461 , fols. $25 \mathrm{v}-26$

${ }^{25}$ Dicho notario, 1463 , fols. $6 \mathrm{v}$ y $18 \mathrm{v}$.

${ }^{26}$ Dicho notario, 1465 , fol. $73 \mathrm{v}$.

${ }^{27}$ Z.APN, Antón de Abiego, 1475, fol. 6v.

${ }^{28}$ Dicho notario, 1484, fols. $18 \mathrm{y}$ tutores y curadores de dicha Oro, y a los bienes de los tres, de cualquier petición o demanda que ella u otro en su nombre pudieran hacerles en el futuro. A continuación, en dicho lugar y en presencia del notario cristiano y los testigos, Beatriz se personó en las casas de Sento Amiello, tejedor del lugar. Alli y ante todos ellos, Beatriz manifestó que un día del anterior mes de junio, en Zaragoza, se dirigió a ella Simuel Sumiel, que residía en Épila y que estaba en la ciudad por el luto del difunto presbítero mosén García de Soria. Le habló, en presencia del tejedor zaragozano Juan Ximénez y como cuñado y marido de su hermana Duenya Abenbitas, en relación «al deudo» entre las tres hermanas y a la parte que a ella le pudiera corresponder de los bienes de sus difuntos padres. Luego le dijo

«como era espossada mi ermana Oro con el fijo de Ento Amiello, a su pesar»,

continuó explicando Beatriz, para terminar aconsejándole que

"yo fuese a Epila y que me dentrase por las casas y heredades y tomasse de los bienes mobles que fueron de mi padre y madre ..., que el me ayudaria en quanto yo quisiesse y que suyo esto azia, como el me lo dezia, quel me los mercaria y me daria por ellos todo quanto yo quisiesse».

Viendo, terminó de exponer Beatriz, que lo decía

«malivolament con muchas y diversas cautelas, otras me se sacaba»,

le contestó que no

«sabia lo que a mi parte venia, que yo yria a Epila y que veria lo que era mio»;

y esto por

«ycharlo de mi, viendo su mal fin, enganyo y malicia que andava por enganyarme e defraudarme cautelosament» ${ }^{29}$.

Una vez explicada la convesación que con ella tuvo su cuñado Simuel y aclarada su postura a Sento Amiello, objeto de su viaje al lugar de Urrea, Beatriz requirió al notario para que levantara acta de todo lo expuesto.

${ }^{29}$ L.A.APN., Martín Ramo, 1491, fols. 86v-88v: testigos con el ganadero zaragozano Juan de Monreal y el molinero Sebastián Domingo, de Plasencia, el sastre Mosse Aroffos y el zapatero Salamon Ayach, ambos de Epila. 
La mala intención, el engaño, el ofrecimiento de ayuda y el interés de Simuel Sumiel, respecto a su cuñada Beatriz, recuerdan mucho al que tuvo Acach Abenforna con su pupila Ceti Leredi, madre de aquélla. La historia de la desgraciada y rebelde Ceti, en cuanto a malos consejos, pudo verse repetida en su hija Beatriz, aunque no en una cuestión tan fundamental como su matrimonio. Por lo que respecta a su hermana Oro, no está claro si se casó «a su pesar» o si a quien le pareció mal el matrimonio fue a su cuñado Simuel. De todos ellos daré más noticias en otra ocasión.

\section{RESUMEN}

Este estudio está dedicado a la inconformista personalidad de Ceti Leredi, la judía que intentó rebelarse contra su concertado matrimonio con Jaco Abenbitas. Ceti, hija de Hahim Leredi y de Duenya Gallur, residió en Épila, villa aragonesa đel señorío de los Ximénez de Urrea, en el siglo XV.

\section{SUMMARY}

This article describes the incomformist personality of Ceti Leredi, the Jewish woman who tried to rebel against her mariage, previously settled, to Jaco Abenbitas. Ceti, Hahim Leredi's and Duenya Gallur's daughter, lived in Epila, an Aragonese village pertaining to the dominion of the Ximénez de Urrea family, in the 15th century. 